\title{
Cultura de paz e formação universitária em saúde: diálogos possíveis a partir de terreiros de umbanda
}

Manoel Guedes de Almeida', Débora Regina Marques Barbosa², José Ivo dos Santos Pedrosa ${ }^{3}$

\section{Resumo}

Este trabalho aborda os conceitos e os pilares sustentadores da cultura de paz na formação universitária a partir de pesquisa etnográfica qualitativa em terreiro de umbanda na cidade de Teresina, Piauí, Brasil, no ano de 2012. Ao considerar a abordagem multiculturalista do processo de formação e a constituição sociocultural da realidade, este texto aborda pontos importantes da construção da cultura de paz a partir da criação de espaços de diálogos entre distintas culturas nos espaços de ensino-aprendizagem.

\section{Palavras-chave}

Formação Universitária. Cultura de Paz. Saúde e Cultura. Cultura Afro-brasileira.

1. Graduando em Medicina na Universidade Federal do Piauí, militante e membro da coordenação nacional da ANEPOP (Articulação Nacional de Extensão Popular). E-mail: manoel.medufpi@gmail.com.

2. Graduanda em Enfermagem no Instituto de Ensino Superior Múltiplo, membro do Grupo de Estudos em Saúde Pública da Universidade Federal do Piauí. E-mail: ddebora.regina@gmail.com.

3. Doutor em Saúde Pública pela Universidade Estadual de Campinas, professor adjunto IV do Centro de Ciências da Saúde da Universidade Federal do Piauí. E-mail: jivopedrosa@gmail.com. 


\title{
Culture of peace and higher education in health: possible dialogues from umbanda temples
}

Manoel Guedes de Almeida*, Débora Regina Marques Barbosa**, José Ivo dos Santos Pedrosa***

\begin{abstract}
This paper discussed the concepts and the pillars of support of the culture of peace in higher education from a qualitative and ethnographic research done at a Umbanda temple in Teresina, Piauí state, Brazil, in 2012. Considering the multiculturalist approach to the educational process and the sociocultural construction of reality, this paper discusses important issues about the culture of peace construction from the creation of dialogue spaces between different cultures in teaching and learning spaces.
\end{abstract}

\section{Keywords}

Higher Education. Culture of Peace. Health and Culture. African-Brazilian Culture.

\footnotetext{
* Undergraduate student in Medicine at the Federal University of Piauí, militant and member of the national coordination of ANEPOP (Articulação Nacional de Extensão Popular). E-mail: maniel_medufpi@gmail.com.

** Graduated in Nursing of the Multiple Higher Education Institute, member of the Public Health Study Group of the Federal University of Piauí. E-mail: ddebora_regina@gmail.com.

** Doctor in Public Health from the State University of Campinas, professor at the Sciences Health Center at the Federal University of Piauí. E-mail: jivopedrosa@gmail.com.
} 


\section{Introdução}

A cultura africana, segundo Guimarães (1990), sofreu várias transformações no Brasil, constituindo uma mescla estruturada e diversa de hábitos e crenças entre essas duas nações, que se acentuou marcadamente desde o tráfico negreiro até os dias atuais. Àquela época, a necessidade de constituição de uma nação negra que albergasse os focos de cultura importados da África nos navios negreiros culminou com as insurreições das quais os livros de histórias positivistas tratam. É nessa conjuntura política e cultural que os quilombos surgiram e se desenvolveram como estrutura social, como foco de resistência não apenas política, quanto à fuga da repressão física, mas também como marco simbólico vívido da necessidade imperativa de afirmação da etnia de um povo que vivenciava uma identidade sem corpo, em busca da territorialização. No Piauí, a situação não foi diferente, mas teve uma roupagem particular. Até o final do século $X X$, a história oficial negava a escravidão - tanto a indígena quanto a negra - no estado e reforçava nas escolas a assertiva da inexistência da cultura negra na região, entrando em desacordo com intelectuais, pesquisadores e militantes do Movimento Negro Piauiense Organizado. Essa situação culminou em protestos e reivindicações, contribuindo, de certa forma, para a formulação de políticas de fomento às ações afirmativas e para o respeito e o reconhecimento das manifestações culturais e religiosas afrodescendentes.

Desde o início da construção do Brasil, delineou-se uma frente triangular de confronto de culturas diversificadas (sobretudo europeia, africana e indígena), sob a hegemonia e a dominação da cultura branca, europeia e clerical. A dominação foi exercida à custa da força física ou do direito legitimador da lei que regulava a vida das colônias segundo o ponto de vista ético e moral da metrópole. A hegemonia foi exercida no campo do conhecimento cartesiano e ortodoxo, tomado como verdade absoluta, e no desconhecimento e na anulação das verdades subjetivas que envolviam as singularidades do modo de viver e pensar o mundo do "colonizado", do "lado de baixo do Equador", justificando, dessaforma, a escravidão, a perseguição, o massacre, a expropriação da terra, do direito e da liberdade de pensar segundo as verdades que lhes fossem próprias.

Nesse cenário, Guimarães (1998) afirma que a única forma de sobrevivência encontrada pela cultura africana no Brasil foi dissolverse e homogeneizar-se, mascarar e disfarçar crenças, costumes e hábitos, distanciandose de suas raízes mais profundas em um processo de absorção gradual pela cultura dominante, dando origem ao sincretismo religioso, que, no Brasil, evidencia as marcas históricas e culturais deixadas por esses povos no constructo do organismo brasileiro.

Os terreiros, nesse contexto, representam os resquícios da resistência cultural, religiosa e política afrodescendente, o local de aglutinação de costumes e crenças africanas e de cultos não somente evidentes nos rituais, mas na referência ao passado como dispositivo afirmador de uma identidade étnica e cultural.

Segundo Silva (2007), totalizando hoje mais de 30.000 em todo o território nacional, os terreiros são marginalizados e expropriados pela especulação imobiliária e relegados à periferia das cidades ou à zona rural, localidades onde pouco se percebe a presença do Estado e de políticas públicas voltadas à saúde e à melhoria da qualidade de vida. Nesses espaços de precariedade, existe a possibilidade de se desenvolver e criar força uma nova subjetividade, que valorize o culto e o símbolo frente a um futuro desprovido de esperanças. É nesse ambiente, afirma Sodré (1988), que a cultura de terreiro toma corpo e 
voz, uma voz mansa, porém constante, difusora de saberes sociais e de verdades históricas de comprovação empírica, muitas vezes de existência ou veracidade ignoradas pela cultura dominante reproduzida e perpetuada pelas instituições formais da sociedade Constituem, pois, em última instância, não apenas uma resistência cultural, mas um foco de resistência política, um espaço de ajuda e de moralidade mútua, que comungam desejos e futuros ignorados pelo todo social. Fica clara, então, a "invisibilização" desse setor da sociedade civil que, como vários outros, nunca conseguirá, de fato, a consecução de direitos sociais constitucionalizados em 1988 e vive tão marginalizado socialmente quanto em tempos de Palmares.

É nesse contexto que se faz necessária a construção de uma cultura de paz, que segundo Diski e outros (2004), constitui-se no conjunto de valores, atitudes, tradições e comportamentos baseados no respeito à vida, no fim da violência, na promoção e prática da não violência, com pleno respeito dos direitos humanos e das liberdades fundamentais, bem como na solução pacífica de conflitos, no direito à liberdade de qualquer tipo, à justiça, à democracia, à diversidade cultural, à informação, à opinião etc. Em seu conjunto, deixa claro que a população brasileira afrodescendente pouco outorga os direitos que, segundo a autora, Ihes são irrefutáveis.

Seria reducionista, no entanto, entender a paz estritamente como não violência. Na visão de Minayo (1994), a compreensão do fenômeno apenas seria possível se entendido como processo, segundo a dialética interioridade/ exterioridade, na qual a violência é parte integrante não só da racionalidade histórica, mas da origem da própria consciência. Tratar de um tema tão complexo de maneira fatídica, segundo a autora, é ir de encontro ao diálogo, ao reconhecimento e à edificação das civilizações, como mostraram Hegel (1980), Freud (1974),
Habermas (1980), dentre outros, devendo a paz ser entendida numa rede de processos sociais e psicológicos. Não há, sob a ótica de Freire (1996) e de Ceccim (2002), modo de transformação social sem a qual não se tenha a sociedade como início e fim e a educação como ponte única e edificadora, cujo elo mais íntimo no tocante à prática seja a Universidade.

Diante desse contexto, o presente trabalho tem por objetivo abordar a construção de uma cultura de paz a partir de elementos da formação universitária tradicional.

\section{Metodologia}

Esta é uma pesquisa etnográfica com abordagem qualitativa. Etnográfica por implicar na descrição e no estudo de um fenômeno ou realidade. Para tanto, em um primeiro momento, os pesquisadores identificaram, na cidade de Teresina, Estado do Piauí, Brasil, no ano de 2012, os representantes comunitários e espirituais, para os quais fizeram visitas regulares, com o objetivo de levantar informações e vivências relacionadas à cultura afrodescendente e à cultura de paz. Em um segundo momento, as informações colhidas foram confrontadas com o referencial teórico construído a partir de grupos de discussão, sendo qualitativa ao considerar esses dados observacionais e o referencial teórico como substratos às questões e análises fundamentais à confecção deste trabalho.

\section{Resultados}

A intersubjetividade aqui abordada tratase da forma com que os indivíduos de um determinado grupo e contexto social interagem mutuamente e envolvem o outro - o non-self - na construção do próprio, do self, que é entendido por eles como verdade irrefutável e exteriorizado em sua ética e ações. Essas verdades, em um contexto mais amplo, são perpetuadas por 
instituições diversas, como família, amigos, religiões, escolas e Universidades, esta última assumindo destaque no presente trabalho por representar o elo mais íntimo entre a ciência e o mundo da vida (COELHO JúNIOR et al., 2004).

Essa abordagem fenomenológica vai de encontro à edificação das Universidades, que consideram o eu como uma entidade posta e desconsidera o outro na construção do self, denominado por Blumer (1986) de interacionalismo simbólico. Dessa forma, como já afirmara, em 1910, Mead (1978), tutor de Blumer, a consciência é produto da construção simbólica, dotada de significados, e dos papéis sociais compartilhados mutuamente, articulados em sistemas ou instituições que regulam as ações em determinada sociedade, criando tipos sociais e tipificando o sujeito. Seria, então, a partir desse eu generalizado ou institucional, que a identidade self individual poderia se construir e se estabilizar ao passo que se alinha a um tipo humano socialmente determinado.

A identificação do non-self pelo estudante universitário frente à comunidade, então, assume feições características do impasse entre subjetividades divergentes, a self científica generalizada e institucionalizada e a self de grupos não hegemônicos, como o afrodescendente. Sob a ótica de Pagliosa (2008), como instituição a Universidade forma profissionais não apenas tecnicamente, mas incumbe em seus ideários verdades próprias da cultura dominante. No campo da saúde, essa hegemonia é mantida por um modelo positivista extremamente medicalizado, instrumentalizado, tecnicista, strictu sensu, cujos focos ideológicos no mundo apareceram por volta de 1910, mas foi sistematizado por Abrahan Flexner em seu polêmico trabalho, intitulado Medical Education in the United States and Canada - A Report to the Carnegie Foudation for the Advancement of Teaching, que ficou conhecido por Relatório Flexner (Flexner Report), que orientava, de forma decisiva, as políticas e ações em saúde no último século. Desse relatório decorreram as formas com que a saúde é abordada pelas instituições de ensino em quase todo o mundo, ou seja, curativista, baseada na técnica e em conferências, com aulas expositivas pautadas na memorização. Esse tipo de formação, todavia, deixa a desejar quanto a aspectos sociais por desconsiderar do processo saúde-doença aspectos para além do biológico, como a historicidade dos povos e suas relações com eles mesmos e com os outros, o ambiente e sua saúde e/ou doença.

Segundo Gazzinelli e outros (2005), apesar das análises críticas que se pronunciaram nas últimas décadas sobre Educação em Saúde, que consideram aspectos mais amplos tanto da saúde quanto da doença, abarcando conceitos mais modernos da docência e novas técnicas de aprendizagem - desde a Nova Escola Pragmática, de John Dewey, a Paulo Freire, dentre outros essas inovações conceituais não representaram mudanças significativas se não no campo das ideias. Acrescenta que essas reflexões não têm sido traduzidas em intervenções significativas nas universidades, que, segundo os autores:

Continuam utilizando métodos e
estratégias dos modelos teóricos da
psicologia comportamental, acarretando,
em decorrência, um profundo hiato entre
teoria e prática, enquanto esta permanece
pautada em concepções behavioristas e
deterministas, a teoria demonstra superação
dessas concepções em detrimento de uma
abordagem da doença mais compreensiva e
interpretativa. (GAZZINELLI et al., 2005, p.
1).

Sobre o behaviorismo, também conhecido como comportamentalismo, Skinner (1972) afirmatratar-sedoconjuntodeteoriaspsicológicas que ponderam sobre o comportamento humano mais adequado segundo estímulos específicos. Uma crítica recorrente a essa teoria é que ela não aborda aspectos psicológicos e simbólicos no tocante à relação ser-estímulo, 
desconsiderando que pessoas diferentes podem e geralmente respondem de maneira diferente aos estímulos desencadeadores de respostas. Apesar disso, como bem retrata os autores supracitados, as universidades mantêm seu ensino pautado em teorias ultrapassadas, construindo, dessa maneira, profissionais para uma realidade social há décadas transformada.

Segundo Silva (2007), os templos afroreligiosos, há séculos, são espaços de inclusão social de grupos excluídos, constituindo substrato ao desenvolvimento de rituais e vivências interpessoais ricas. Em seu conjunto, essas práticas possibilitam a sobrevivência de uma intersubjetividade dialógica e histórica que cedem lugar ao acolhimento, à promoção e à prevenção da saúde com base na renovação paulatina de tradições milenares, sobretudo quanto ao uso de ervas medicinais empiricamente consagradas (PEDROSA, 2005). Mas não apenas isso: cada gesto traz no seu bojo uma carga simbólica sem dimensões, de modo que cada indivíduo torna-se parte e entende-se como parte de um todo coletivo, cultural e histórico. Seria o borrão de limites entre a verdade coletiva e a pessoal.

A intersubjetividade afrodescendente, acrescenta Guimarães (2003), desenvolveu-se no Brasil e institucionalizou-se em terreiros, que, assim como as Universidades, professam uma verdade no campo da fenomenologia que pouco dialoga no decurso da formação acadêmica. Sendo assim, essa outra subjetividade, a afro, e todas as outras non-selfs aos campi, são "coisificadas", ou pior, ignoradas do processo de formação. Essa identificação de si como diferente, essa tipificação da sociedade - tão bem enfatizada por Berger e Luckmann (1966) e predita por Sartre (1943) - converge para o que este último chamou de "vergonha", a identificação do outro como diferente. Como consequência imediata frente a esse choque de verdades alheias, três possibilidades mostramse presentes: fuga, indiferença e confronto.
É nesse contexto antropológico complexo que se inserem as relações entre a Universidade, os profissionais em seu seio albergados e as demais instituições sociais. No caso particular da cultura afrodescendente, a questão fica bem definida: por muitos anos as políticas públicas, e aqui se incluem as Diretrizes Curriculares Nacionais norteadoras da formação docente em todo o país, ignoraram a existência de outra cultura "verdadeira" que não a hegemônica, cientificista. Tudo isso após o período de perseguição orientado por políticas desse gênero aos povos negros e outros grupos culturais, religiosos ou não, culminando com a tipificação do outro "não científico" como inferior e relegando-o a um patamar social de subserviência. O outro, dessa maneira, identificou-se como estranho ao todo, ao self institucional - um eu sem etnia - "envergonhando-se" dessa condição e relegando-se, ele próprio, à periferia de qualquer mobilização social.

Desse modo, assim como, em 1934, já propusera Dewey (2010), nos Estados Unidos, e Freire (1996), no Brasil, a Universidade deveria constituir-se instrumento de mobilização social ao inserir o estudante para além dos muros de sua estrutura, pondo-o em contato com culturas diversas, fazendo-o conviver com outras subjetividades, com as quais ele dificilmente interagiria. Além disso, Freire enfatiza que, considerar a comunidade apenas como laboratório, como propôs Dewey e como geralmente fazem várias universidades, limitando a práxis à prática observacional, exclui-se do processo de formação a interação social na intensidade necessária à construção de simbolismos, do tornar-se parte. Para tanto, as relaçõesentreestudanteecomunidadedevemser orgânicas, com troca mútua de saberes, medos, frustrações e anseios; devem, impreterivelmente, haver agressões culturais brandas, tanto no estudante quanto na comunidade, como fruto inevitável da convivência - ou co-vivências - 
para que essas microagressões convirjam, no fim, para o esfacelamento da linha divisória entre o self e o non-self, entre a ciência e a sociedade, o instante em que culturas diversas identifiquem-se com um todo institucional.

Caso esse caminho não seja trilhado, teríamos como consequência final e fatal o confronto, por vezes relatado nos anais da história deste país. Quando grupos sociais diversos competem por um mesmo espaço ideológico ou expandem-se a ponto de o convívio ser impossível é quase sempre inevitável haver confronto, que pode ser simbólico ou físico, sendo ambos igualmente desastrosos e tão lesivos que podem resultar na extinção de um determinado grupo social. Apesar de a cultura de paz ter sido um tema recorrente e uma preocupação constante das Nações Unidas e da UNESCO (Organização das Nações Unidas para a Educação, a Ciência e a Cultura), essa cultura faz parte de um contexto mais amplo e a paz vai muito além da não violência. Como bem aborda Valle e outros (2002, p. 15):

[...] esta cultura se fundamenta em aspectos relacionados com a educação e os esforços têm se centrado no apoio ao desenvolvimento de programas especiais de ensino com ênfase na educação para a paz, tolerância e a não violência.

Existem, todavia, várias formas de paz além da não violência, mas todas divergem de um ponto comum: o choque entre simbolismos alheios aos olhos no instante em que o convívio com o outro invisível torna-se inevitável.

\section{Considerações finais}

Como já aborda Minayo (2001), entender a paz como um processo e a cultura da paz como fruto de interações sociais complexas, que consideram não apenas o indivíduo na construção da realidade, mas o todo coletivo e dinâmico que o envolve, aponta para a assertiva maior de que medidas intervencionistas no sentido de seu desenvolvimento deva se proceder no âmbito da educação sob a ótica freiriana.

Nesse sentido, o papel de destaque das Universidades, "para o bem ou para o mal" (PAGLIOSA; DA ROS, 2008), reproduz no estudante a cultura dominante do saber científico, extirpando de seu processo de formação saberes e conhecimentos mais amplos, pluriculturais, associados ao mundo da vida, à experiência social. Assim, culturas outras, tais como as relativas à crença e à espiritualidade são, então, "invisibilizadas" durante a formação, gerando eventos duplamente lesivos: ao estudante despreparado para lidar com questões além do self científico - sobra o choque cultural, a agressão causada pelo estranho, pelo outro; e à comunidade-sobre a qual recaem as ações frutos desse despreparo - a subserviência simbólica e a vergonha sartreanas frente a uma cultura dominante com poder opressor em potencial.

Sob o prisma dessa conjuntura, fazse imperativa a necessidade de inserir o estudante para além dos muros da academia, para além, inclusive, do pragmatismo, inserilo na comunidade como parte constituinte. A Universidade, então, como instrumento formador de subjetividades, deveria tornar-se um espaço rico de interações com grupos culturais diversos, fazendo com que o afrodescendente tenha importância por sua grande influência na construção da identidade nacional. Dessa forma, é necessário que a Nação constitua sujeitos que percebam a existência das diversidades e valorize a integração do estudante na comunidade e a vivência dele com diferentes grupos sociais, de modo a formar seres conscientes de si e de sua relação com o mundo e com outras verdades. Apenas assim se construirá, de fato, a cultura de paz tão largamente abordada. 


\section{Referências}

BERGER, P. L.; LUCKMANN, T. A construção social da realidade: tratado de sociologia do conhecimento. 31. ed. Petrópolis: Vozes, 1966.

BLUMER, H. Symbolic interactionism: perspective and method. Englewood Cliffs, New Jersey: Prentice-Hall: 1986.

CECCIM, R. B.; CAPOZZOLO, A. A. A educação dos profissionais de saúde e afirmação da vida: a prática clínica como resistência e criação. In: MARINS, J. J. N. et al. (Orgs.). Educação médica em transformação: instrumentos para a construção de novas realidades. São Paulo: Abem/Hucitec, 2004.

CECCIM, R. B.; FEUERWERKER, L. C. M. Mudança na graduação das profissões de saúde sob o eixo da integralidade. Cad. Saúde Pública, Rio de Janeiro, v. 20, n. 5, p. 1400-1410, 2004. Disponível em: <http://dx.doi.org/10.1590/S0102-311X2004000500036>. Acesso em: 22 abr. 2014.

COELHO JUNIOR, N. E.; FIGUEIREDO, L. C. Figuras da intersubjetividade na constituição subjetiva: dimensões da alteridade. Interações, Campo Grande, v. 9, n. 17, p. 9-28, jun. 2004.

DEWEY, J. A arte como experiência. Tradução de Vera Ribeiro. São Paulo: Martins Fontes, 2010.

DISKIN, L; ROIZMAN, G. L. Paz, como se faz? Semeando cultura de paz nas escolas. Rio de Janeiro: Governo do Estado do Rio de Janeiro; UNESCO: Associação Palas Athena, 2002.

FREIRE, P. Educação como prática de liberdade. 30. ed. São Paulo: Paz e Terra, 2007.

. Pedagogia da autonomia: saberes necessários à prática educativa. São Paulo: Paz e Terra, 1996.

GAZZINELLI, M. F. et al. Educação em saúde: conhecimentos, representações sociais e experiências da doença. Cad. Saúde Pública, Rio de Janeiro, v. 21, n. 1, p. 200-206, jan.-fev. 2005.

GUIMARÃES, C. F; MENEGUEL, S. N. Subjetividade e saúde coletiva: produção de discursos a re-significação do processo saúde-doença no pós-moderno. Revista mal-estar e subjetividade, Fortaleza, v. 3, n. 2, p. 353-371, set. 2003.

GUIMARÃES, M. A. C. É um umbigo, não é? A mãe criadeira, um estudo sobre o processo de construção de identidade em comunidades de terreiro. 1990. Dissertação (Mestrado em Psicologia Clínica),Pontifícia Universidade Católica do Rio de Janeiro, Rio de Janeiro, I990.

. A área de ilusão e a subjetividade afrodescendente no Brasil. Arayê, Rio de Janeiro, Ano II, p. 17-22, set. 1998.

HABERMAS, J. Conhecimento e interesse. Rio de Janeiro: Zahar, 1982.

MEAD, G. H. What social objects must psychology presupose? In: LUCKMANN, T. (Ed.) Phenomenology and sociology. Harmondsworth, UK: Penguin Books, 1978.

MINAYO, M. C. S. Estrutura e sujeito, determinismo e protagonismo histórico: uma reflexão sobre a 
práxis da saúde coletiva. Ciênc. saúde coletiva, Rio de Janeiro, 2001, v. 6, n.1, p. 7-19. Disponível em: <http://dx.doi.org/10.1590/S1413-81232001000100002>. Acesso em: 23 abr. 2014.

PAGLIOSA, F. L., DA ROS, M. A. O Relatório Flexner: para o bem e para o mal. Revista Brasileira de Educação Médica, Rio de Janeiro, v. 32, n. 4, p. 492-499, 2008.

PEDROSA, J. I. S. Prefácio. In: SILVA, J. M. da; DACACH, S.; LOPES, F. Atagbá: guia para a promoção da saúde dos terreiros. Rio de Janeiro: Rede Nacional de Religiões Afro-Brasileiras e Saúde, 2005.

SARTRE, J. P. O ser e o nada: ensaio de ontologia fenomenológica. Tradução de Paulo Perdigão. Petrópolis: Vozes, 1997.

SILVA, J. M. Religiões e saúde: a experiência da Rede Nacional de Religiões Afro-Brasileiras e Saúde. Saúde Soc., São Paulo, v.16, n. 2, p.171-177, 2007.

SKINNER, B. F. Reflections on behaviorism and society. Prentice-Hall: Englewood Cliffs, 1972 (Century Psychology Series).

Sobre o Behaviorismo. Tradução de Maria da Penha Villalobos. São Paulo: Cultrix, 1974.

SODRÉ, M. O terreiro e a cidade. Petrópolis: Vozes, 1988.

VALLE, D. et al. Cultura de paz. México: Guías Informativas, 2002.

Submetido em 6 de fevereiro de 2014.

Aprovado em 3 de março de 2014. 